\title{
Cloud cover-adjusted ultraviolet B irradiance and pancreatic cancer incidence in 172 countries
}

\author{
Cedric F. Garland, Dr.P.H., F.A.C.E. ${ }^{1}$, Raphael E. Cuomo, M.P.H., C.P.H. ${ }^{2,3}$ \\ Edward D. Gorham, M.P.H., Ph.D. ${ }^{1}$, Kenneth Zeng, B.S. ${ }^{1}$, and Sharif B. Mohr, M.P.H., Ph.D. ${ }^{1}$ \\ ${ }^{1}$ Division of Epidemiology, Department of Family and Preventive Medicine, University of \\ California, La Jolla CA \\ ${ }^{2}$ Division of Global Health, Department of Family and Preventive Medicine, University of \\ California, La Jolla CA \\ ${ }^{3}$ Graduate School of Public Health, San Diego State University San Diego CA
}

Length: Abstract: 226 words; Text: 1894 words; Tables: 2; Figures: 2; Appendix Tables: 1

Keywords: Pancreatic cancer, ultraviolet rays, incidence, UVB, vitamin D, epidemiology, international comparisons

Corresponding author: Raphael Cuomo, M.P.H., C.P.H., Division of Global Health, Department of Family and Preventive Medicine, University of California, La Jolla CA 920930620,cuomo@rohan.sdsu.edu 


\begin{abstract}
Background: Controversy exists regarding whether vitamin D deficiency could influence etiology of pancreatic cancer. Several cohort studies have found that high serum 25hydroxyvitamin D [25(OH)D] concentrations are associated with low risk of pancreatic cancer, while others have not.

Hypothesis: Low ultraviolet B irradiance is associated with high incidence of pancreatic cancer. Methods: Age-standardized pancreatic cancer incidence rates were obtained from GLOBOCAN in 2008. The association between cloud-adjusted UVB irradiance and age-standardized incidence rates of pancreatic cancer was analyzed using regression.

Results: Overall, the lower the cloud-adjusted UVB irradiance, the higher the incidence rate of pancreatic cancer. Residents of countries with low UVB irradiance had approximately 6 times the incidence rates as those in countries with high UVB irradiance $(p<0.0001$ for males and $p<$ 0.0001 for females). This association persisted after adjustment for traditional risk factors of pancreatic cancer ( $p<0.0001$ for males and $p<0.0001$ for females).

Conclusions: There was an inverse association of cloud-adjusted UVB irradiance with incidence of pancreatic cancer that persisted after adjustment. This result is consistent with an inverse association of overall vitamin D deficiency in countries with lower UVB irradiance with risk of pancreatic cancer. Further research on the role of 25(OH)D in reduction of pancreatic cancer in individuals would be desirable to expand the limited avenues available for prevention of this highly fatal disease.
\end{abstract}




\section{INTRODUCTION}

There were estimated 337,872 new cases of pancreatic cancer and 330,372 deaths in 2012 [1]. In the US, there were 42,885 new cases and 41,509 deaths [1]. Smoking, excessive alcohol consumption, and intake of large amounts of red meat have been reported as being associated with higher than usual risk of pancreatic cancer [2-8]. A previous ecological study in 2002 found an inverse association between latitude and a measure of solar ultraviolet B (UVB) irradiance and incidence rates of pancreatic cancer worldwide [9]. Exposure to solar UVB irradiance is the source of approximately 95\% of circulating 25-hydroxyvitamin D, the principal vitamin D metabolite [10]. Vitamin D and its metabolites have been linked to lower incidence and mortality from several cancers [11-14], but the results have been mixed, with some studies failing to detect benefit $[15,16]$.

Six years have passed since the earlier analysis using the 2002 data from GLOBOCAN [9]. An updated analysis is needed since more recent data are available and many rates have changed due to shifts in cultural, political, and economic factors. It is also desirable since a new method for display of the association of solar UVB with incidence rates has been created that reveals a clearer association between UVB irradiance and risk than has been shown before: a stratified method according to hemisphere and cancer incidence [17]. This new method allows visualization of the symmetry of this association in two hemispheres. It could be useful for future studies of association between UVB irradiance and risk of any disease.

\section{METHODS}


We obtained age-standardized incidence rates of pancreatic cancer from the International Agency for Research on Cancer (IARC) GLOBOCAN 2008 database [18], a recent source of age-standardized incidence and mortality rates by country. Intake of energy from animal sources and alcohol consumption were obtained from the United Nations Food and Agriculture Organization [19]; prevalence of obesity, sex-specific smoking prevalence, and per capita health expenditure data were obtained from the World Health Organization [20]; and prevalence of diabetes was obtained from the International Diabetes Federation [21].

Total solar UVB irradiance, adjusted for cloud cover, was calculated using data from the National Aeronautics and Space Administration (NASA) International Satellite Cloud Climatology Project (ISCCP) satellite [22] and astronomical data on geographic variation in solar irradiance [23]. The total noon solar irradiance at the top of the atmosphere for each country on the date of the winter solstice was calculated using the formula $\mathrm{A}^{\prime}=\mathrm{A} * \cos (\mathrm{x}+23.5$ degrees $)$ in the northern hemisphere; and $\mathrm{A}^{\prime}=\mathrm{A} * \cos (\mathrm{x}-23.5$ degrees $)$ in the southern hemisphere; where $\mathrm{x}=$ latitude of the population centroid of the country in degrees, $\mathrm{A}=$ total solar radiation at the equator in Watts (W) per square meter $\left(\mathrm{m}^{2}\right)$ (i.e., the solar constant, 1366 $\mathrm{W} / \mathrm{m}^{2}$ ), and $\mathrm{A}^{\prime}=$ total solar radiation in $\mathrm{W} / \mathrm{m}^{2}$ for the country on the date of the winter solstice [23]. Since UVB is approximately $0.4 \%$ of total solar irradiance, total solar irradiance was multiplied by 0.004 to obtain the estimated UVB irradiance at the top of the atmosphere. UVB was then corrected for percentage cloud cover, according to data from the ISCCP satellite, using the following formula: UVB irradiance x (1 - fractional cloud cover). Population centroids were calculated by the Columbia University Center for International Earth Science Information Network [24]. 
Incidence rates of sex-specific, age-adjusted rates of pancreatic cancer were plotted against cloud cover-adjusted UVB irradiance. A polynomial trend line was added to show the best fit. UVB values in the northern hemisphere were plotted as positive numbers. To stratify the hemispheres, UVB values for countries in the Southern hemisphere were plotted as negative numbers, a common convention in cartographic analyses. This method of plotting is analogous to the plotting approach we have previously used for latitude. It provides a parabola when the highest incidence rates are in countries far from the equator and the lowest are in countries nearest the equator. It would be a flat line if there were no association of UVB with incidence rates. No attempt was made to correct for ozone thickness, since it was found in preliminary analyses to be strongly positively correlated with percentage cloud cover. All calculations for these graphs were performed using JMP, version 10.0.0 (Cary NC: SAS Institute).

Multiple linear regression was used to investigate the association between cloud cover-adjusted UVB irradiance and age-adjusted pancreatic cancer incidence rates, while controlling for prevalence of obesity and diabetes; per capita consumption of animal protein and alcohol; sexspecific smoking prevalence, and per capita health expenditure. One regression model was created for males (Table 1) and another was created for females (Table 2). All analyses were performed using SAS Version 9.3 (Cary NC: SAS Institute).

\section{RESULTS}

Incidence rates of pancreatic cancer were generally higher in countries with lower UVB irradiance. This is illustrated in Figures 1 and 2, where values to the left of the center are for 
countries in the Southern hemisphere, and values to the right of the center are for countries in the Northern hemisphere.

UVB irradiance adjusted for cloudiness was inversely associated with pancreatic cancer in the multiple regression model for males (Table 1) and the multiple regression model for females (Table 2). Consumption of animal protein was positively associated with incidence of pancreatic cancer in both sexes (Tables 1 and 2). Each of the regression models in this study explains approximately three-quarters of the variation in pancreatic cancer incidence worldwide (Tables 1 and 2). The relationship between UVB irradiation and pancreatic cancer incidence persisted in both sexes despite controlling for six covariates. This is consistent with other regression results on the relationship between UVB irradiation and cancer incidence [25,26].

\section{DISCUSSION}

We are not aware of any previous studies that have used cloud cover-adjusted UVB irradiance as the independent variable for incidence of pancreatic cancer. Instead, latitude or clear-air UVB irradiance has been used, due to the historical difficulty of estimating cloud cover worldwide before the existence of the NASA-ISCCP satellite data set. The data from this satellite have now made this feasible [22]. This is a worthwhile advance, since there are many places in the world where UVB irradiance reaching the surface is strongly influenced by cloud cover. A previous paper on pancreatic cancer did not plot incidence rates according to cloud-adjusted UVB irradiance [9]. It had greater dispersion of the points around the prediction line that was based on latitude. Use of latitude as the independent variable accounts for the major effect of solar zenith angle on UVB irradiance, but does not take variations in cloud cover into account. While that 
study used cloud cover-adjusted UVB for some analyses, it did not use it constructing graphs of incidence rates, which this study does. The new approach to analyzing the association between UVB irradiance and age-standardized incidence rates yield far fewer outliers and a much smoother curve. The new data display methodology used here helps to confirm the inverse association of low solar UVB with incidence rates of pancreatic cancer by showing that the curves are similar in the Northern and Southern hemispheres. The similarity of the association in the two hemispheres helps to rule out solely cultural explanations for the higher rates in countries with low UVB irradiance, and is a point in favor of a geophysical factor such as solar UVB irradiance.

These results support the hypothesis that vitamin D levels account for a large amount of global variation in pancreatic cancer. However, it should be noted that certain countries with high dietary vitamin D intake (notably Norway and Sweden) have persistently high rates of pancreatic cancer $[27,28]$. As this suggests, low serum vitamin D is not the sole contributor to pancreatic cancer risk. For this reason, the regression analyses in this study have controlled for animal protein consumption, diabetes prevalence, obesity prevalence, alcohol consumption, sex-specific smoking prevalence, and healthcare expenditures. Several further behavioral factors may protect against pancreatic cancer, including higher folate consumption [29] or possibly the use of nonsteroidal anti-inflammatory drugs [30]. Certain genetic polymorphisms may also increase risk, although several of these polymorphisms influence the vitamin D pathway, such those for the CYP2R gene [31].

\section{$\underline{\text { Weaknesses }}$}


Complete data on all variables were not available for all countries, which may have biased the results. However, missing data for covariates were mostly for countries near the equator that have low incidence rates of pancreatic cancer. In general, missing data for some countries would tend to weaken measures of association between UVB irradiance and age-adjusted incidence rates of pancreatic cancer. This study could not account for all possible confounders and the regression model cannot account for all variables that have an impact on vitamin D photosynthesis in humans, such as type of clothing worn, misdiagnosis rate, or time spent outdoors. Therefore, some degree of misclassification may have occurred. On the other hand, UVB irradiance may affect a broad range of individuals, and an independent negative association between UVB irradiance and incidence rates of pancreatic cancer by country was still present in this study, despite the possibility of exposure misclassification.

Results of ecological studies are generally used to stimulate the formation of novel hypotheses. This is because findings from ecological analyses may not be applicable to individuals. For inherently ecological variables, such as exposure to sunlight, ecological studies may be less prone to error that might occur for non-ecological covariates such as physical activity [32]. However, despite the substantial limitations of the ecological approach, analysis of the global differences in pancreatic cancer incidence and UVB irradiance provide a large-scale natural experiment. Such large-scale natural experiments have identified important associations of great public health impact such as the studies of water fluoridation and incidence of dental carries [33].

\section{$\underline{\text { Strengths }}$}


This study is consistent with findings for analyses of cancer incidence in the United States $[34,35]$ and the world [36,37]. It is the first study to analyze variations in pancreatic cancer incidence according to ultraviolet B when adjusting for cloud cover using NASA satellite data. The significant negative association between age-standardized pancreatic cancer incidence and cloud cover-adjusted UVB persisted even after adjustment for six known confounders.

\section{$\underline{\text { Conclusion }}$}

Further observational studies of individuals on the relationship between serum 25(OH)D and risk of pancreatic cancer are needed to fully assess a possible beneficial effect of vitamin D on risk of pancreatic cancer. To avoid missing this possible benefit, it may be prudent to correct vitamin D deficiency whenever detected in the population. Serum 25(OH)D can be tested for this purpose. The recommended target concentration of 25(OH)D is currently 40-60 ng/ml (100-150 nmol/L), according to a letter signed by many respected vitamin D scientists and physicians [11].

\section{Acknowledgements}

The authors would like to express their deep gratitude and appreciation to Captain Gregory Utz, MD, United States Navy Medical Corps for his many contributions and steadfast support of this research program and his outstanding leadership as the Commanding Officer of the Naval Health Research Center from 2011-2013 and as U.S. Department of Defense Attaché to Viet Nam during 2014. The authors also thank Dr. M. Ferlay and the International Agency for Research on Cancer for providing the GLOBOCAN database used for this study and NASA for the cloud cover data. 
The positions expressed in this article are solely those of the authors, and do not represent official positions of the Bureau of Medicine and Surgery, Department of the Navy, Department of Defense, or the U.S. Government. 


\section{REFERENCES}

1. International Agency for Research on Cancer (2012) GLOBOCAN 2012 Database: http://globocan.iarc.fr/. Accessed December 2013.

2. Lowenfels AB, Maisonneuve P (2005) Risk factors for pancreatic cancer. J Cell Biochem 95: 649-656.

3. Michaud DS (2004) Epidemiology of pancreatic cancer. Minerva Chir 59(2): 99-111.

4. Larsson SC, Wolk K, Brismar K, Wolk A (2005) Association of diet with serum insulin-like growth factor I in middle-aged and elderly men. Am J Clin Nutr 81: 1163-1167.

5. Lu XH, Wang L, Li H, Qian JM, Deng RX, et al. (2006) Establishment of risk model for pancreatic cancer in Chinese Han population. World J Gastroenterol 12: 2229-2234.

6. Go VL, Gukovskaya A, Pandol SJ (2005) Alcohol and pancreatic cancer. Alcohol 35: 205211.

7. Nothlings U, Wilkens LR, Murphy SP, Hankin JH, Henderson BE, et al. (2005) Meat and fat intake as risk factors for pancreatic cancer: the multiethnic cohort study. J Natl Cancer Inst 97: 1458-1465.

8. Larsson SC, Hakanson N, Permert J, Wolk A (2006) Meat, fish, poultry and egg consumption in relation to risk of pancreatic cancer: a prospective study. Int J Cancer 118: 2866-2870.

9. Mohr SB, Garland CF, Gorham ED, Grant WB, Garland FC (2010) Ultraviolet B irradiance and vitamin $\mathrm{D}$ status are inversely associated with incidence rates of pancreatic cancer worldwide. Pancreas 39: 669-674.

10. Adams JS, Clemens TL, Parrish JA, Holick MF (1982) Vitamin-D synthesis and metabolism after ultraviolet irradiation of normal and vitamin-D-deficient subjects. N Engl J Med 306: 722-725.

11. Garland C, Gorham E, Garland F (2009) Vitamin D for cancer prevention: global perspective. Ann Epidemiol (In Press).

12. Cuomo RE, Mohr SB, Gorham ED, Garland CF (2013) What is the relationship between ultraviolet B and global incidence rates of colorectal cancer? Dermato-Endocrinology 5: 181185.

13. Mohr SB, Garland CF, Gorham ED, Grant WB, Garland FC (2010) Ultraviolet B irradiance and incidence rates of bladder cancer in 174 countries. Am J Prev Med 38: 296-302.

14. Mohr SB, Gorham ED, Garland CF, Grant SF, Garland CF (2010) Low ultraviolet B and increased risk of brain cancer: An ecological study of 175 countries. Neuroepidemiology 35: 281-290. 
15. Stolzenberg-Solomon RZ, Vieth R, Azad A, Pietinen P, Taylor PR, et al. (2006) A prospective nested case-control study of vitamin $d$ status and pancreatic cancer risk in male smokers. Cancer Res 66: 10213-10219.

16. Stolzenberg-Solomon R, Jacobs E, Arslan A, Qi D, Patel A, et al. (2010) Circulating 25hydroxyvitamin D and risk of pancreatic cancer. American Journal of Epidemiology 172: 8193.

17. Garland C, Mohr S, Gorham E, Grant W, Garland F (2006) Role of ultraviolet B irradiance and vitamin D in prevention of ovarian cancer. Am J Prev Med 31: 512-514.

18. Parkin DM, Bray F, Ferlay J, Pisani P (2001) Estimating the world cancer burden: Globocan 2000. Int J Cancer 94: 153-156.

19. United Nations Food and Agriculture Organization FAOSTAT Food and Agriculture database. Available from:http://www.fao.org/geonetwork/srv/en/main.search. Accessed 10 July 2011.

20. World Health Organization (2009) WHO Report on the Global Tobacco Epidemic. Geneva, Switzerland.

21. International Diabetes Federation (2011) Diabetes Atlas.

22. National Aeronautics and Space Administration International Satellite Cloud Climatology Project database.

23. National Aeronautics and Space Administration Solar Radiation and the Earth System. http://edmall.gsfc.nasa.gov/inv99Project.Site/Pages/science-briefs/ed-stickler/edirradiance.html.

24. Columbia University Center for International Earth Science Information Network (CIESIN). http://www.ciesin.org/. Accessed 30 August 2011.

25. Mizoue T (2004) Ecological study of solar radiation and cancer mortality in Japan. Health Physics 87: 532-538.

26. Mohr SB, Garland CF, Gorham ED, Grant WB, Garland FC (2010) Ultraviolet B irradiance and vitamin $\mathrm{D}$ status are inversely associated with incidence rates of pancreatic cancer worldwide. Pancreas 00: 1-6.

27. Lips P, Duong T, Oleksik A, Black D, Cummings S, et al. (2001) A global study of vitamin D status and parathyroid function in postmenopausal women with osteoporosis: baseline data from the multiple outcomes of raloxifene evaluation clinical trial. J Clin Endocrinol Metab 86: 1212-1221.

28. Van der Wielen R, Lowik MR vdBH, de Groot LC, Haller J, Moreiras O, van Staveren WA (1995) Serum vitamin D concentrations among elderly people in Europe. Lancet 346: 207210. 
29. Larsson SC, Giovannucci E, Wolk A (2006) Folate intake, MTHFR polymorphisms, and risk of esophageal, gastric, and pancreatic cancer: a meta-analysis. Gastroenterology 131: 12711283.

30. Anderson KE, Johnson TW, Lazovich D, Folsom AR (2002) Association between nonsteroidal anti-inflammatory drug use and the incidence of pancreatic cancer. Journal of the National Cancer Institute 94: 1168-1171.

31. Anderson LN, Cotterchio M, Knight JA, Borgida A, Gallinger S, et al. (2013) Genetic variants in vitamin $\mathrm{D}$ pathway genes and risk of pancreas cancer; results from a populationbased case-control study in Ontario, Canada. PLoS One 8.

32. Robinson W (1950) Ecological correlations and the behavior of individuals. American Sociological Review 15: 351-357.

33. Dean HT, Arnold FA, Jr., Jay P, Knutson JW (1950) Studies on mass control of dental caries through fluoridation of the public water supply. Public Health Rep 65: 1403-1408.

34. Garland CF, Garland FC (1980) Do sunlight and vitamin D reduce the likelihood of colon cancer? Int J Epidemiol 9: 227-231.

35. Boscoe FP, Schymura MJ (2006) Solar ultraviolet-B exposure and cancer incidence and mortality in the United States, 1993-2002. BMC Cancer 6: 264.

36. Grant WB, Garland CF (2006) The association of solar ultraviolet B (UVB) with reducing risk of cancer: multifactorial ecologic analysis of geographic variation in age-adjusted cancer mortality rates. Anticancer Res 26: 2687-2699.

37. Grant WB, Mohr SB (2009) Ecological studies of ultraviolet B, vitamin D and cancer since 2000. Ann Epidemiol 19: 446-454. 
Table 1. Multiple linear regression models for age-standardized pancreatic cancer incidence rates according to cloud-adjusted UVB irradiance, males, 111 countries, 2008

\begin{tabular}{|c|c|c|c|c|}
\hline Covariate & $\begin{array}{c}\text { Regression } \\
\text { coefficient }\end{array}$ & $\begin{array}{c}\text { Standard } \\
\text { error }\end{array}$ & $t$ & $p$ \\
\hline Solar UVB irradiance, Watts/m² & -0.18905 & 0.07883 & -2.40 & 0.0182 \\
\hline Animal protein consumption, kcal/capita/year & 0.00216 & 0.00090 & 2.38 & 0.0190 \\
\hline Diabetes prevalence, \% & 0.02986 & 0.05378 & 0.56 & 0.5800 \\
\hline Obesity prevalence, \% & 0.00551 & 0.01177 & 0.47 & 0.6408 \\
\hline Alcohol consumption, kcal/capita/year & 0.01409 & 0.00295 & 4.77 & $<0.0001$ \\
\hline Male Smoking Prevalence, \% & 0.04205 & 0.01477 & 2.85 & 0.0053 \\
\hline Health Expenditure, US dollars/person/year & 0.00001 & 0.00030 & 0.04 & 0.9679 \\
\hline Intercept & 1.75413 & 1.31371 & 1.34 & 0.1847 \\
\hline
\end{tabular}


Table 2. Multiple linear regression models for age-standardized pancreatic cancer incidence rates according to cloud-adjusted UVB irradiance, females, 111 countries, 2008

\begin{tabular}{|c|c|c|c|c|}
\hline Covariate & $\begin{array}{c}\text { Regression } \\
\text { coefficient }\end{array}$ & $\begin{array}{c}\text { Standard } \\
\text { error }\end{array}$ & $t$ & $p$ \\
\hline Solar UVB irradiance, Watts/m² & -0.15378 & 0.05049 & -3.05 & 0.0029 \\
\hline Animal protein consumption, kcal/capita/year & 0.00151 & 0.00062 & 2.46 & 0.0156 \\
\hline Diabetes prevalence, \% & 0.02103 & 0.03604 & 0.58 & 0.5608 \\
\hline Obesity prevalence, \% & 0.0084 & 0.00784 & 1.13 & 0.2622 \\
\hline Alcohol consumption, kcal/capita/year & 0.00365 & 0.00206 & 1.78 & 0.0784 \\
\hline Female Smoking Prevalence, \% & 0.03061 & 0.01652 & 1.85 & 0.0668 \\
\hline Health Expenditure, US dollars/person/year & 0.00014 & 0.00021 & 0.69 & 0.4939 \\
\hline Intercept & 2.42139 & 0.74589 & 3.25 & 0.0016 \\
\hline
\end{tabular}


Appendix Table 1. Countries included in this study, including three-letter country code, country name, age-standardized male pancreatic cancer incidence (cases per 100,000), age-standardized female pancreatic cancer incidence (cases per 100,000), and cloud cover-adjusted ultraviolet B $\left(\mathrm{W} / \mathrm{m}^{2}\right)$

\begin{tabular}{|c|c|c|c|c|}
\hline $\begin{array}{c}\text { Three- } \\
\text { Letter } \\
\text { Country } \\
\text { Code }\end{array}$ & Country Name & $\begin{array}{l}\text { Male Pancreatic } \\
\text { Cancer } \\
\text { Incidence }\end{array}$ & $\begin{array}{c}\text { Female } \\
\text { Pancreatic } \\
\text { Cancer } \\
\text { Incidence }\end{array}$ & $\begin{array}{l}\text { Cloud Cover- } \\
\text { Adjusted } \\
\text { Ultraviolet B }\end{array}$ \\
\hline AFG & Afghanistan & 2.1 & 2.1 & 7.18578 \\
\hline ALB & Albania & 10.6 & 5.5 & 5.08767 \\
\hline DZA & Algeria & 1.5 & 1 & 11.90406 \\
\hline AGO & Angola & 1.1 & 1.3 & 17.62383 \\
\hline ARG & Argentina & 8.5 & 6.3 & 6.28936 \\
\hline ARM & Armenia & 12.7 & 8 & 8.11503 \\
\hline AUS & Australia & 6.7 & 5.1 & 8.59460 \\
\hline AUT & Austria & 8.9 & 6.6 & 5.25448 \\
\hline AZE & Azerbaijan & 3.7 & 3.1 & 8.11503 \\
\hline BHR & Bahrain & 4.3 & 1.4 & 12.98325 \\
\hline BGD & Bangladesh & 0.4 & 0.4 & 12.55048 \\
\hline BRB & Barbados & 5.9 & 3.6 & 10.32185 \\
\hline BLR & Belarus & 7 & 3.4 & 3.39654 \\
\hline BEL & Belgium & 6.6 & 4.8 & 3.03030 \\
\hline BLZ & Belize & 2.3 & 3 & 7.82842 \\
\hline BEN & Benin & 1.3 & 0.9 & 12.45062 \\
\hline BTN & Bhutan & 2.5 & 4.6 & 12.87090 \\
\hline BOL & Bolivia & 2.7 & 2.6 & 9.97535 \\
\hline $\mathrm{BIH}$ & Bosnia \& Herzegovina & 6.5 & 3.2 & 4.84953 \\
\hline BWA & Botswana & 1 & 0.3 & 15.82686 \\
\hline BRA & Brazil & 4.3 & 3.4 & 10.30337 \\
\hline BRN & Brunei & 5.5 & 4.6 & 7.67480 \\
\hline BGR & Bulgaria & 10.1 & 5.4 & 4.93038 \\
\hline BFA & Burkina Faso & 0.7 & 1.1 & 13.65886 \\
\hline BDI & Burundi & 1 & 0.8 & 15.15248 \\
\hline KHM & Cambodia & 1.7 & 1.3 & 12.19855 \\
\hline CMR & Cameroon & 1.4 & 0.6 & 12.45062 \\
\hline CAN & Canada & 6.6 & 5.2 & 2.40765 \\
\hline CPV & Cape Verde & 0 & 0.4 & 9.25750 \\
\hline CAF & Central African Republic & 1.4 & 0.8 & 12.42605 \\
\hline TCD & Chad & 1.5 & 0.9 & 15.81391 \\
\hline CHL & Chile & 5.3 & 5.4 & 6.56992 \\
\hline $\mathrm{CHN}$ & China & 3.2 & 2.4 & 8.88426 \\
\hline
\end{tabular}




\begin{tabular}{|c|c|c|c|c|}
\hline COL & Colombia & 3.1 & 2.9 & 7.68544 \\
\hline $\mathrm{COM}$ & Comoros & 0 & 0 & 16.69626 \\
\hline COG & Congo & 1.7 & 0.9 & 15.40896 \\
\hline COD & Congo, DRC & 1.4 & 2.3 & 15.17040 \\
\hline CRI & Costa Rica & 5.4 & 4.5 & 11.38116 \\
\hline CIV & Cote d'Ivoire & 0.9 & 0.7 & 11.44416 \\
\hline HRV & Croatia & 9 & 5.5 & 5.44768 \\
\hline CUB & Cuba & 5.1 & 4.1 & 9.44034 \\
\hline CYP & Cyprus & 3.7 & 1.4 & 6.70565 \\
\hline CZE & Czech Republic & 11.8 & 7.9 & 3.79092 \\
\hline DNK & Denmark & 9 & 7.4 & 3.23106 \\
\hline CJI & Djibouti & 0.9 & 0 & 14.65293 \\
\hline $\mathrm{DOM}$ & Dominican Republic & 2.8 & 3.3 & 10.01616 \\
\hline ECU & Ecuador & 3.6 & 3.9 & 7.70448 \\
\hline EGY & Egypt & 2.8 & 1.5 & 11.58381 \\
\hline SLV & El Salvador & 2.4 & 2.9 & 14.01645 \\
\hline GNQ & Equatorial Guinea & 0 & 0.3 & 12.51978 \\
\hline ERI & Eritrea & 1.2 & 0.9 & 14.41857 \\
\hline EST & Estonia & 9.8 & 5.1 & 3.96816 \\
\hline ETH & Ethiopia & 1.4 & 1 & 14.26740 \\
\hline FJI & Fiji & 2 & 1 & 10.82256 \\
\hline FIN & Finland & 9 & 7.4 & 3.37736 \\
\hline FRA & France & 6.7 & 4.8 & 4.95053 \\
\hline GAB & Gabon & 0.9 & 0.2 & 11.37780 \\
\hline GEO & Georgia & 3.6 & 2.4 & 5.00976 \\
\hline DEU & Germany & 8.8 & 6.1 & 4.24242 \\
\hline GHA & Ghana & 0.9 & 1 & 11.44416 \\
\hline GRC & Greece & 7.2 & 4.4 & 5.23908 \\
\hline GUM & Guam & 4.5 & 2.4 & 7.50680 \\
\hline GTM & Guatemala & 2.4 & 2.8 & 9.81152 \\
\hline GIN & Guinea & 0.8 & 0.5 & 12.28955 \\
\hline GNB & Guinea-Bissau & 1.5 & 1.4 & 11.30388 \\
\hline GUY & Guyana & 3.1 & 3.8 & 9.59350 \\
\hline HTI & Haiti & 3.9 & 2.8 & 10.01616 \\
\hline HND & Honduras & 3.6 & 3.6 & 9.30230 \\
\hline HUN & Hungary & 12.4 & 7.4 & 4.59767 \\
\hline ISL & Iceland & 3.2 & 3.9 & 2.03490 \\
\hline IND & India & 1.1 & 0.8 & 12.66944 \\
\hline IDN & Indonesia & 3.1 & 2.5 & 12.75372 \\
\hline IRN & Iran & 1.6 & 1.1 & 9.39194 \\
\hline IRQ & Iraq & 1.6 & 1.3 & 8.88426 \\
\hline IRL & Ireland & 6.2 & 5.4 & 2.89800 \\
\hline ISR & Israel & 11.7 & 7.8 & 7.42959 \\
\hline ITA & Italy & 8.1 & 6 & 5.63472 \\
\hline JAM & Jamaica & 4.5 & 3.8 & 10.99056 \\
\hline
\end{tabular}




\begin{tabular}{|c|c|c|c|c|}
\hline JPN & Japan & 10 & 6.1 & 5.84325 \\
\hline JOR & Jordan & 4 & 2.3 & 8.25510 \\
\hline KAZ & Kazakhstan & 9.8 & 5.8 & 4.51094 \\
\hline KEN & Kenya & 4.1 & 3 & 9.62920 \\
\hline KWT & Kuwait & 3.2 & 5.9 & 9.26541 \\
\hline KGZ & Kyrgyzstan & 4.8 & 4 & 5.08767 \\
\hline LAO & Laos & 1.3 & 1.1 & 11.90644 \\
\hline LVA & Latvia & 9.9 & 4.9 & 4.19608 \\
\hline LBN & Lebanon & 3.4 & 2.8 & 7.18578 \\
\hline LSO & Lesotho & 0.2 & 0.5 & 12.63465 \\
\hline LBR & Liberia & 0.9 & 0.6 & 12.45062 \\
\hline LBY & Libya & 5.1 & 2.9 & 12.01284 \\
\hline LTU & Lithuania & 10.5 & 5.2 & 4.30808 \\
\hline LUX & Luxembourg & 8.7 & 6.9 & 3.15910 \\
\hline MKD & Macedonia & 7.4 & 2.6 & 5.00976 \\
\hline MDG & Madagascar & 2 & 0.7 & 16.93090 \\
\hline MWI & Malawi & 0.1 & 0.5 & 12.98598 \\
\hline MYS & Malaysia & 2.4 & 1.8 & 7.69384 \\
\hline MLI & Mali & 2.3 & 2.7 & 9.20990 \\
\hline MLT & Malta & 7.3 & 4.9 & 6.23280 \\
\hline MRT & Mauritania & 1.4 & 1.3 & 9.50208 \\
\hline MUS & Mauritius & 1.7 & 0.8 & 10.69320 \\
\hline MEX & Mexico & 4.5 & 4 & 9.75128 \\
\hline FSM & Micronesia & 4.5 & 2.4 & 4.72675 \\
\hline MDA & Moldova & 7.9 & 4.9 & 4.68293 \\
\hline MNG & Mongolia & 3.3 & 3.4 & 6.56810 \\
\hline MAR & Morocco & 2.2 & 1.2 & 11.02532 \\
\hline $\mathrm{MOZ}$ & Mozambique & 1.1 & 1.1 & 13.52820 \\
\hline MMR & Myanmar & 1.5 & 1.3 & 13.39380 \\
\hline NAM & Namibia & 0.6 & 0.5 & 17.14577 \\
\hline NPL & Nepal & 1.4 & 1.7 & 13.60464 \\
\hline NLD & Netherlands & 6.9 & 5.3 & 2.96450 \\
\hline NZL & New Zealand & 5.8 & 4.7 & 2.86272 \\
\hline NIC & Nicaragua & 3 & 3.6 & 8.44515 \\
\hline NER & Niger & 1.9 & 1 & 13.42338 \\
\hline NGA & Nigeria & 1.2 & 1.2 & 13.27802 \\
\hline PRK & North Korea & 3.9 & 3.7 & 7.79100 \\
\hline NOR & Norway & 7.6 & 6.2 & 3.16491 \\
\hline OMN & Oman & 1.5 & 1.8 & 13.39380 \\
\hline PAK & Pakistan & 0.9 & 0.7 & 10.00860 \\
\hline PAN & Panama & 3.5 & 3.9 & 9.51160 \\
\hline PNG & Papua New Guinea & 1 & 0.4 & 8.03012 \\
\hline PRY & Paraguay & 4.2 & 3.4 & 6.98320 \\
\hline PER & Peru & 3.3 & 3.7 & 9.33940 \\
\hline PHL & Philippines & 2.3 & 1.8 & 9.41990 \\
\hline
\end{tabular}




\begin{tabular}{|c|c|c|c|c|}
\hline POL & Poland & 8.2 & 5 & 3.55740 \\
\hline PRT & Portugal & 4.8 & 2.6 & 7.11018 \\
\hline PRI & Puerto Rico & 4.9 & 2.6 & 10.99056 \\
\hline QAT & Qatar & 3.8 & 3.7 & 13.09245 \\
\hline ROM & Romania & 10.3 & 5.2 & 4.68293 \\
\hline RUS & Russia & 8.4 & 4.6 & 3.37071 \\
\hline RWA & Rwanda & 2.3 & 1.4 & 15.16368 \\
\hline WSM & Samoa & 1.4 & 0 & 11.04180 \\
\hline SAU & Saudi Arabia & 4 & 3.5 & 12.21962 \\
\hline SEN & Senegal & 1.5 & 1.3 & 9.81152 \\
\hline SRB & Serbia \& Montenegro & 7.4 & 4.8 & 4.84953 \\
\hline SLE & Sierra Leone & 0.8 & 0.5 & 12.39784 \\
\hline SGP & Singapore & 5.1 & 3.7 & 2.88876 \\
\hline SVK & Slovakia & 10.4 & 6.2 & 3.79092 \\
\hline SVN & Slovenia & 9.9 & 6.2 & 5.35192 \\
\hline SLB & Solomon Is. & 0.9 & 0.9 & 11.26860 \\
\hline SOM & Somalia & 2.2 & 1.6 & 12.32959 \\
\hline ZAF & South Africa & 5.3 & 4.3 & 12.31860 \\
\hline KOR & South Korea & 8 & 4.7 & 6.63957 \\
\hline ESP & Spain & 7 & 4.1 & 7.00844 \\
\hline LKA & Sri Lanka & 0.8 & 0.5 & 4.77925 \\
\hline SDN & Sudan & 1.2 & 0.7 & 15.81391 \\
\hline SUR & Suriname & 2.6 & 1.7 & 5.76408 \\
\hline SWZ & Swaziland & 0.4 & 0.6 & 12.78480 \\
\hline SWE & Sweden & 4.5 & 4.1 & 3.16491 \\
\hline $\mathrm{CHE}$ & Switzerland & 7.4 & 5.2 & 5.35192 \\
\hline SYR & Syria & 1.8 & 1.1 & 7.88900 \\
\hline TJK & Tajikistan & 2.1 & 2.4 & 8.34757 \\
\hline TZA & Tanzania & 0.4 & 0.2 & 12.26043 \\
\hline THA & Thailand & 1.7 & 1.1 & 13.02322 \\
\hline $\mathrm{BHS}$ & The Bahamas & 0.8 & 0.4 & 9.23748 \\
\hline GMB & The Gambia & 1.6 & 2.2 & 11.26020 \\
\hline TGO & Togo & 1.1 & 1 & 12.39784 \\
\hline TTO & Trinidad \& Tobago & 6.6 & 3.3 & 10.39885 \\
\hline TUN & Tunisia & 2.5 & 1.9 & 9.98025 \\
\hline TUR & Turkey & 3.8 & 2.6 & 5.98752 \\
\hline TKM & Turkmenistan & 4.4 & 3.5 & 8.11503 \\
\hline UGA & Uganda & 1.7 & 1.3 & 9.62920 \\
\hline UKR & Ukraine & 8.8 & 4.1 & 3.15910 \\
\hline ARE & United Arab Emirates & 4.3 & 2.9 & 13.09245 \\
\hline GBR & United Kingdom & 6.8 & 5.4 & 2.83045 \\
\hline USA & United States & 8 & 6.1 & 5.50181 \\
\hline URY & Uruguay & 9.2 & 7.9 & 6.36272 \\
\hline UZB & Uzbekistan & 1.8 & 1.7 & 7.99491 \\
\hline VUT & Vanuatu & 1.8 & 1.9 & 10.82256 \\
\hline
\end{tabular}




\begin{tabular}{|l|l|r|r|r|}
\hline VEN & Venezuela & 3.3 & 3.3 & 10.49048 \\
\hline VNM & Vietnam & 0.8 & 0.7 & 11.05188 \\
\hline YEM & Yemen & 2 & 2.3 & 15.81391 \\
\hline ZMB & Zambia & 1.4 & 1 & 16.48836 \\
\hline ZWE & Zimbabwe & 2.9 & 2.6 & 13.36650 \\
\hline
\end{tabular}




\section{FIGURE LEGENDS}

Figure 1. Rates of age-standardized pancreatic cancer incidence (cases per 100,000) in males according to cloud cover-adjusted UVB irradiance (W/m²), 172 countries, 2008

Figure 2. Rates of age-standardized pancreatic cancer incidence (cases per 100,000) in females according to cloud cover-adjusted UVB irradiance (W/m²), 172 countries, 2008 


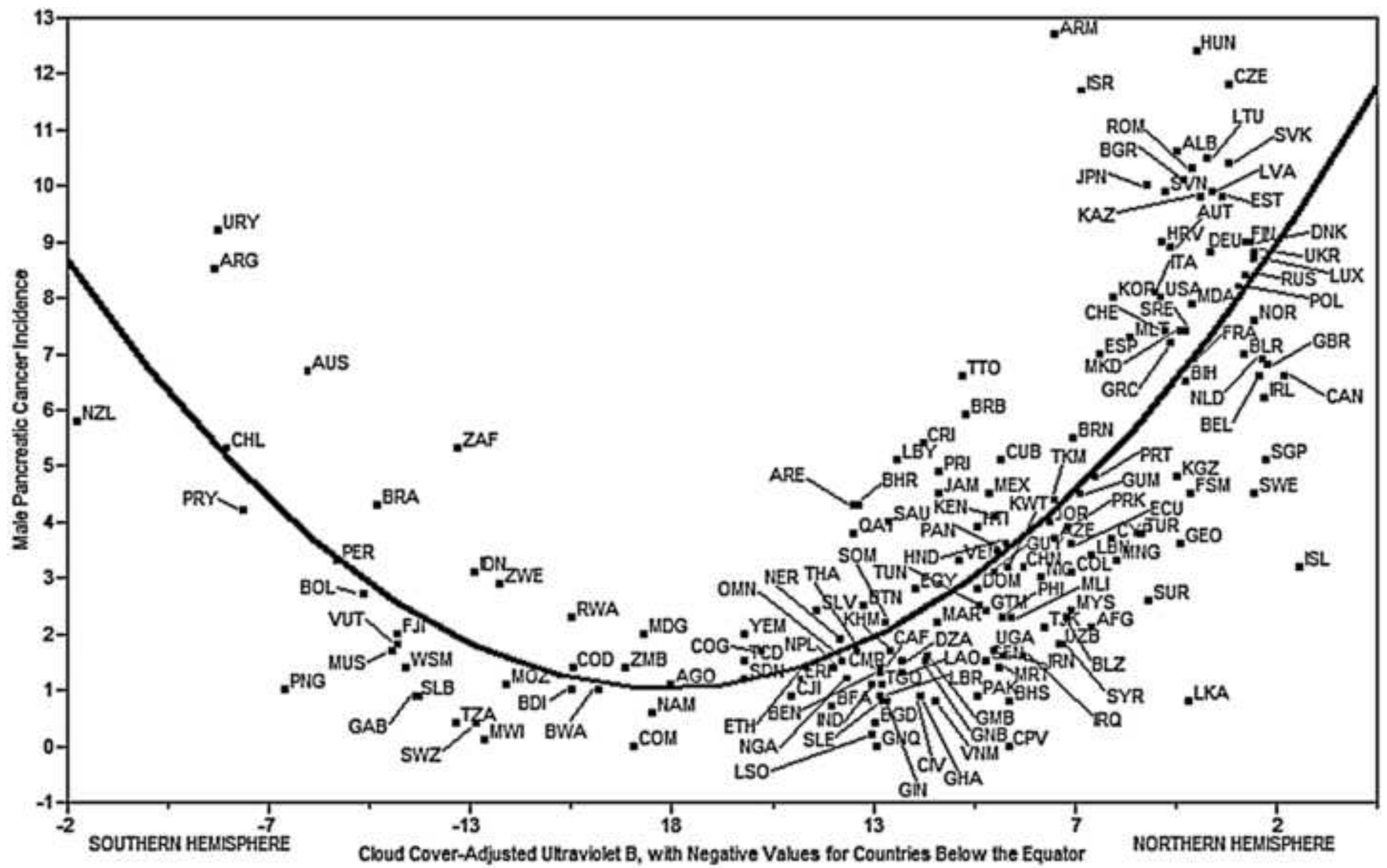




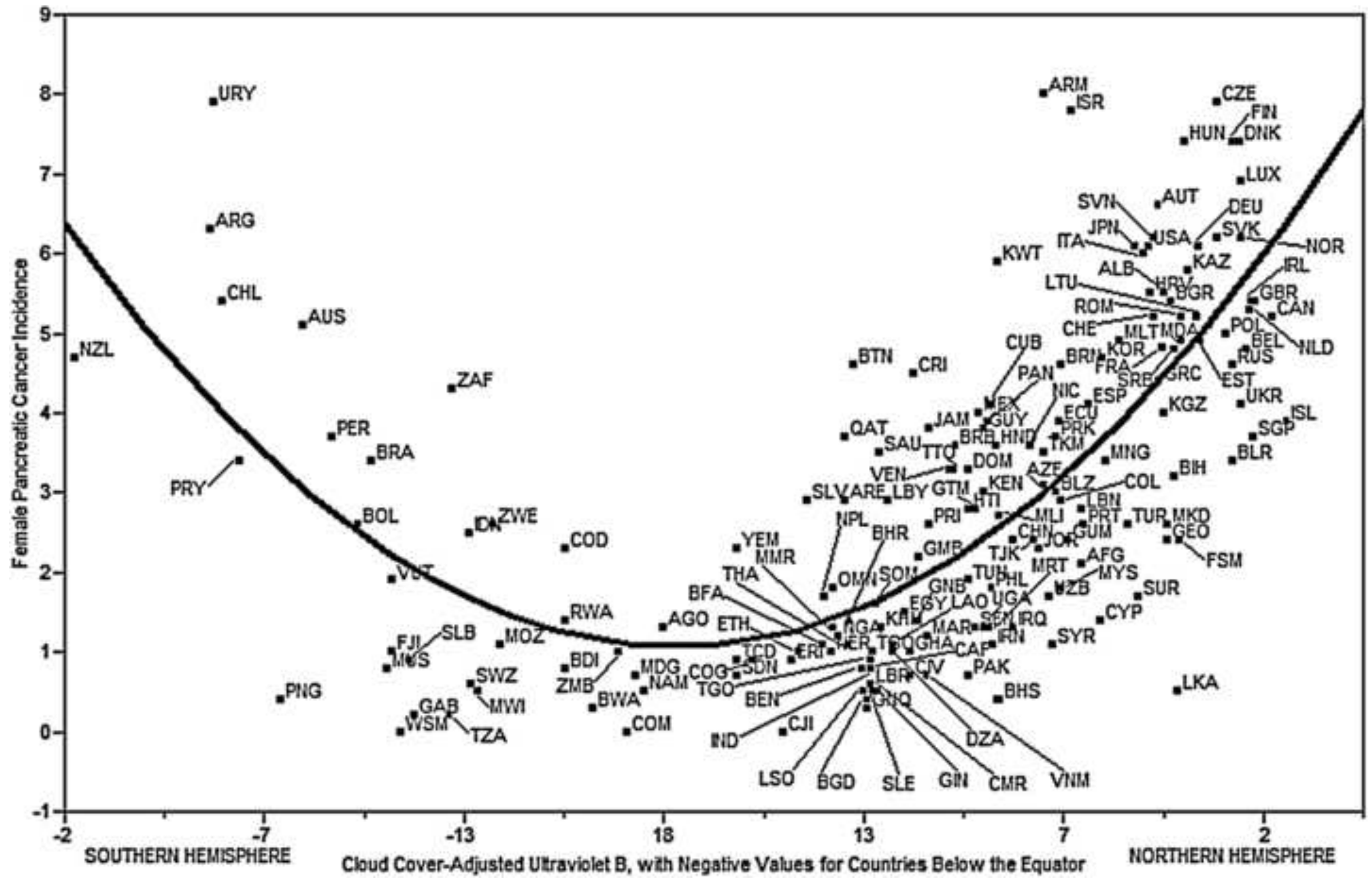

